\title{
Signos de Vida en la Figura de la Síndone de Turín
}

\section{(Signs of Life in the Figure of the Shroud of Turin)}

\author{
BERNARDO HONTANILLA CALATAYUD \\ Catedrático de Cirugía Plástica, Estética y Reparadora. \\ Depto. Cirugía Plástica, Estética y Reparadora. \\ Clínica Universidad de Navarra, Pamplona, España \\ bhontanill@unav.es \\ ORCID: 0000-0001-6186-4791
}

\begin{abstract}
En este artículo se exponen varios signos de vida que presenta la Síndone de Turín. En base al desarrollo de la rigidez cadavérica, se analiza la postura del cuerpo impreso en la Síndone. Igualmente, la presencia de surcos faciales indica que la persona está viva. Por tanto, la Sábana de Turín muestra a la vez signos de muerte como de vida de una persona que dejó su imagen impresa en un momento en el que estaba viva. Si la Síndone es un fraude, se trataría de una obra de arte realizada por un genio con conocimientos médicos, forenses y procesado de imagen de al menos el siglo XX. Si seguimos el relato evangélico observamos que existe una correcta simetría entre los datos presentes en la imagen y lo descrito en los mismos, tanto de la muerte como de la resurrección.
\end{abstract}

Palabras clave: Síndone de Turín; rigor mortis; surcos faciales; Resurrección.

Abstract. In this article several signs of life present in the Shroud of Turin are pointed out. Following the development of rigor mortis, the body posture of the image on the Shroud is analyzed. This, together with the presence of specific facial folds indicate that the person wrapped in it is alive. Therefore, the image on the Shroud of Turin shows both signs of death and life in a person whose image was imprinted when he was alive. 
If this is a fraud case, it should be considered as an artwork performed by a genius with medical, forensic and image processing knowledge from at least the XX century. But if we read the Gospels, a (perfect) remarkable symmetry is found between the data obtained from the image and the events described in the Gospels, both regarding the death and resurrection of Jesus.

Keywords: Shroud of Turin; rigor mortis; facial folds; Resurrection.

\section{Introducción}

En una situación cultural donde el enfrentamiento entre religión y ciencia está todavía vivo, la Sindonología representa un lugar de diálogo constructivo entre razón y fe. Así, el estudio de la Síndone de Turín constituye un buen paradigma del estudio interdisciplinar que demanda la superación del conocimiento fragmentado (Fernández-Capo 2015). El objeto de este estudio es analizar la imagen de la Síndone de Turín bajo el punto de vista de un cirujano plástico. Ahora bien, se hace necesario tener en cuenta los fenómenos cronotanatobiológicos que se suceden tras la muerte de una persona y en especial tras la muerte de una persona sometida a la muerte por crucifixión. No vamos a cuestionar la validez o antigüedad de la Síndone que corresponde a otros métodos de estudio. Solo nos centraremos en dar una explicación de la imagen y la correlacionaremos con los Evangelios para determinar simetrías, equivalencias y correspondencias con la descripción y explicación que llevaremos a cabo. Aunque existen numerosos estudios en la bibliografía que apuntan a que muy probablemente se trata de la Sábana que cubrió el cadáver de Jesucristo (Borrini and Garlaschelli 2019; Meacham 1983; https://www.shroud.com/; Barbet 1953), nosotros vamos a centrarnos en describir si esa imagen procede de un cadáver o bien de un cuerpo vivo.

Barrie Schwortz es un experto en la Sábana Santa y judío practicante, y esto último, dice el experto, hace que su testimonio como científico sea tanto más creíble. La conclusión del equipo del que formó parte (STURP) estableció que la ciencia indica que la Sábana Santa corresponde al lienzo perteneciente a un hombre que fue enterrado de acuerdo a la tradición 
judía, luego de haber sido crucificado de forma coherente a lo que indican los Evangelios. Sin embargo, aclaró que esto no es prueba de la resurrección: "Es una imagen relacionada con la pre-resurrección, ya que si fuera una imagen post-resurrección se trataría de un hombre vivo - no muerto", explicó Schwortz, quien agregó que "la ciencia no puede probar el tipo de imagen que se produciría por un cuerpo humano que ha resucitado de entre los muertos" (Schneible 2015).

A lo largo de este artículo vamos a analizar una serie de signos impresos en la Síndone de Turín que podrían justificar que esa persona envuelta en la Sábana estaba viva en el momento de imprimir su imagen. Para seguir un argumento lógico, se hace primero imprescindible describir los fenómenos que aparecen tras la muerte de una persona, centrándonos en el rigor mortis, y los relacionaremos con los signos de rigidez que podrían ocurrir en la persona que estuvo envuelta en la Síndone.

\section{Rigor mortis}

En muchos de los artículos que hemos consultado se da por hecho, bien de forma tácita y raramente de forma expresa, que la imagen que se forma en la sábana procede de un cadáver que ha sido crucificado. Son escasos los artículos que analizan en profundidad los signos cadavéricos manifestados en la imagen de la Síndone. Sin embargo, en aquellos escasos artículos que sí los describen, con más o menos profundidad (Kori 2018; Villalaín 2010; Bucklin 1982), vamos a basarnos, en parte, para validar nuestra hipótesis. Así, para tener un discurso lógico, primero describiremos los fenómenos que ocurren después de la muerte de una persona.

Inmediatamente tras la muerte, en el cadáver se produce un estado de relajación y flacidez de todos los músculos del cuerpo. Pero al cabo de un tiempo más o menos breve se inicia un lento proceso de contractura muscular, que ha sido llamado rigidez cadavérica o rigor mortis. De la misma forma, esta rigidez desaparecerá en el cadáver progresivamente transcurrido cierto tiempo. La rigidez es visible inicialmente en la mandíbula y la musculatura ocular, después afectará a la cara y pasará al cuello. Posterior- 
mente se extenderá sucesivamente al tórax, a los brazos, al tronco y por último a las piernas. Es decir, sigue un trayecto descendente. Los tiempos habituales de la instauración de la rigidez cadavérica tras el fallecimiento pueden resumirse de la siguiente forma: la contracción de la musculatura esquelética suele iniciarse de las 3 a las 6 horas; suele ser completa en un periodo de 8 a 12 horas (afecta a todo el cuerpo); alcanza su máxima intensidad a las 24 horas e inicia su desaparición a las 36 horas, en el mismo orden en el que se presentó, siendo el período de desaparición progresiva de otras 12 horas (Burkhard 2006). De esta manera, la relajación total de un cadáver, en términos globales, se alcanzaría a las 48 horas después de la muerte (Gráfica I, línea azul). Durante el periodo de instauración de la rigidez, ésta se puede vencer sin desgarros musculares o articulares. Cuando se ha instaurado la intensidad máxima, la rigidez no se puede vencer sin provocar fracturas en los huesos o desgarros musculares. El cadáver se encuentra tan rígido como una tabla. La precocidad, intensidad y duración de esa rigidez va a depender de varios factores, fundamentalmente endógenos, como son la edad, la hidratación, la fiebre del sujeto al morir, las hemorragias, las intoxicaciones y factores externos como la temperatura ambiente siguiendo en gran medida las clásicas leyes de Nysten (Fisher and Fisher 2012).

Fisiopatológicamente, la rigidez va a depender de las reservas de glucógeno del cuerpo y por tanto de la producción del ATP. Actualmente no se conoce exactamente el mecanismo de producción, proponiéndose varias teorías bioquímicas que en definitiva afirman que el ATP (adenosintrifosfato) se transforma en ADP (adenosintrifosfato), liberando una molécula de ácido fosfórico. Este último proporciona el fosfato necesario para la resíntesis del ATP, utilizando como dador de energía el glucógeno. Cuando la reserva de glucógeno se ha agotado, falta energía para resintetizar el ATP y éste se transforma en ADP definitivamente, originando la contracción de la miosina (Martins et al. 2015). Por tanto, el consumo de la reserva de glucógeno es imprescindible para el desarrollo de la rigidez y en el caso de un sujeto que ha muerto como el Hombre de la Sábana ésta tenía que ser mínima. 
Siguiendo las leyes de Nysten, en sujetos musculados e individuos con buena nutrición, la rigidez es tardía, intensa y duradera; a la inversa, la destrucción y las lesiones musculares hacen que la rigidez sea precoz, débil y corta. Abundando en esta idea las personas cansadas, agotadas, desangradas, deshidratadas y con fiebre, como es el caso de la persona envuelta en la sábana, la rigidez aparece precoz y débil (Villalaín 2010). Debe considerarse también la posible actividad muscular violenta previa, originada por traslados, maltratos y crisis asfícticas en la cruz. Burkhard ha estudiado alguno de los factores que modifican la rigidez, entre ellos el ejercicio violento previo a la muerte. En estos casos la rigidez desaparece rápidamente y es precoz, débil y corta (Burkhard 2006). En todos ellos, la disponibilidad de glucógeno y ATP es menor y ambas sustancias son esenciales en la aparición de la rigidez. En este tipo de muerte la hipoglucemia es la regla al agotarse las reservas de glucógeno. Por eso, la actividad muscular, la acidez y la fiebre acortan el proceso. Además, la temperatura media de Jerusalén el día 3 de abril viernes del año 33, que es cuando se ha demostrado que fue crucificado Jesús (Humphreys y Waddington 1983), debió de ser entre $19-23^{\circ} \mathrm{C}$ de máxima y $12-15^{\circ} \mathrm{C}$ de mínima, como así ha ocurrido en los últimos 50 años (https://es.weatherspark.com > Israel > Jerusalem). De esta manera, la calidez del ambiente también contribuiría a que la rigidez fuera muy precoz. En consecuencia, y siguiendo las conclusiones de un estudio (Villalaín 2010), en el caso del Hombre de la Síndone el comienzo de la rigidez habría sido entre los 20 y 45 minutos de la muerte; a la hora, la rigidez sería completa (todo el cuerpo) y máxima intensidad en un período comprendido entre 3 y 6 horas postmortem. Esta rigidez se mantendría en esa intensidad unas 12 horas comenzando su desaparición a lo largo de las 12 horas siguientes, hasta resolverse por completo aproximadamente a las 30-36 horas siguientes de la muerte para dar inicio a la putrefacción. Además, al estar el sujeto en posición vertical se iniciaría la rigidez antes en el cuello y miembros superiores que en las piernas, debido al mayor esfuerzo muscular que ejercen los brazos. Finalmente, el trabajo concluye afirmando que en el sujeto de la Sábana deja impresa su imagen en un rango de tiempo que estaría entre las 3 y 6 horas tras la muerte (Gráfica. 1 línea 
roja). De esta manera, y asumiendo que la imagen impresa es la de Cristo, el autor de la descripción coloca la fecha de la producción de la imagen entre las 19 y 21 horas (falleció sobre la hora nona, nuestras 15 horas) del mismo día y todo en base a la postura de rigidez que presenta el cadáver (Villalaín 2010).

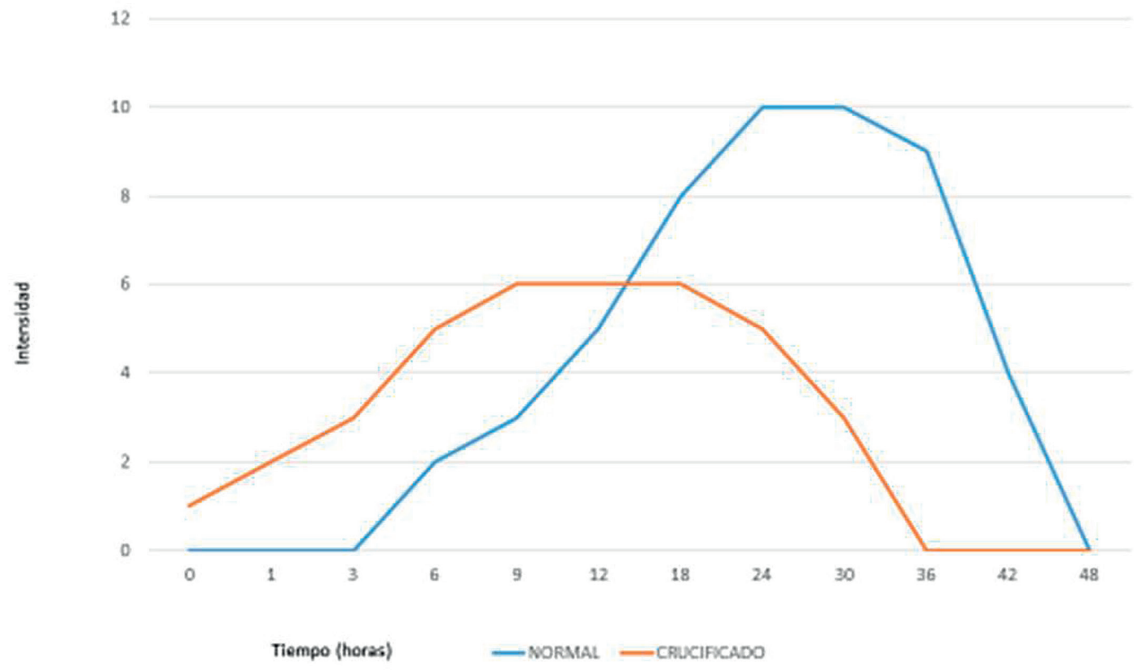

Gráfico 1. Gráfico donde se muestra la evolución de la rigidez postmortem a $22^{\circ} \mathrm{C}$ de una persona normal (línea azul) y la presentada por un crucificado (línea roja)

Sin embargo, los aparentes signos de rigidez que aparecen en la imagen podrían no corresponderse con los signos de rigidez postmortem como clásicamente se han atribuido. Así, en la imagen impresa en la Síndone se aprecia una disposición en semiflexión atípica de los miembros inferiores, una semiflexión de la cabeza y una colocación llamativa de las manos sobre los genitales. A nivel facial, y todavía más sorprendente, observamos una cara que presenta los surcos nasolabiales y nasogenianos marcados. Vamos a describir cada uno de ellos. 


\section{Semiflexión del cuello y semiflexión asimétrica de las articulaciones de la cadera, las rodillas y los tobillos}

Descendiendo caudalmente en el análisis de la figura que nos ocupa, la imagen muestra un cuello en semiflexión que provoca una cierta elevación de la cabeza y mayor intensidad en la impresión de la cara sobre el lino de la sábana al estar más pegado al tejido. Por otro lado, se aprecia una longitud de la imagen global menor en la parte de la sábana que cubría la parte anterior del cuerpo frente a la longitud de la imagen grabada en la parte posterior de la sábana (Fig. 1). Esta distancia mayor de la figura impresa en la parte posterior de la sábana es debida, precisamente, a la semiflexión del cuello que provoca una mayor distancia entre la superficie cutánea posterior del cuello y la superficie de la sábana en su cara posterior. La radiación emitida desde el cuerpo se dispersa y hace que la imagen sea más larga (Fanti 2010). Clásicamente se ha atribuido esta postura de la cabeza a la caída de la misma sobre el tórax en la crucifixión y que posteriormente ha sido fijada por la rigidez cadavérica (Löring 2000). Sin embargo, en las crucifixiones descritas por autores de la época y en colgamientos de guerras del siglo XIX (Arnaud 1880), se describe que las flexiones de la cabeza sobre el tórax cuando el sujeto crucificado muere son tan acentuadas que hunden la cabeza en el tórax a la altura de las escápulas. Igualmente, la imagen presenta la pierna izquierda levemente más flexionada que la derecha estando ésta en discreta rotación interna atribuyendo este signo a que el pie izquierdo estuvo sobre el derecho y ambos clavados con un solo clavo en el madero (Löring 2000, 101, 149) (Fig. 1 y 2). Esa postura es la que daría a entender que un pie estaba sobre el otro y esa postura quedaría fijada posteriormente por la rigidez precoz del cadáver. Precisamente, debido a esta aparente cortedad de una de las piernas por la flexión se ha inferido erróneamente que Cristo era cojo, motivo por el cual se ha representado, sobre todo en el arte sacro ortodoxo, un sedile inclinado (suppedanium) para el apoyo de los pies.

Sin embargo, la rotación de la pierna izquierda que se observa en la sábana, con un discreto mayor grado de flexión que la derecha, no concuerda con la forma que tenían los romanos de crucificar a los condenados 
a ese suplicio. Para observar en tres dimensiones la imagen impresa en la sábana, obsérvese el modelo que ha llevado a cabo el escultor Juan Manuel Miñarro López (Fig. 2). Los pies los clavaban por separado y estos se encontraban apoyados en un sedile con forma de cuerno de rinoceronte, según describe Tertuliano (De anima 56, 8-57). Además, San Cipriano, que había visto crucifixiones, describe la presencia de cuatro clavos en los crucificados (De Cartago 2016). De manera similar lo describen también San Ambrosio, Teodoreto y San Agustín (Fernández-Carvajal 1997, 644). Un reexamen posterior demostró que el clavo que se utilizaba para la crucifixión, que se creía de 17 a $18 \mathrm{~cm}$. de largo, en verdad era de solo $11,5 \mathrm{~cm}$., con lo que cada pie fue clavado de manera independiente a cada lado de la cruz (Zias 1985).
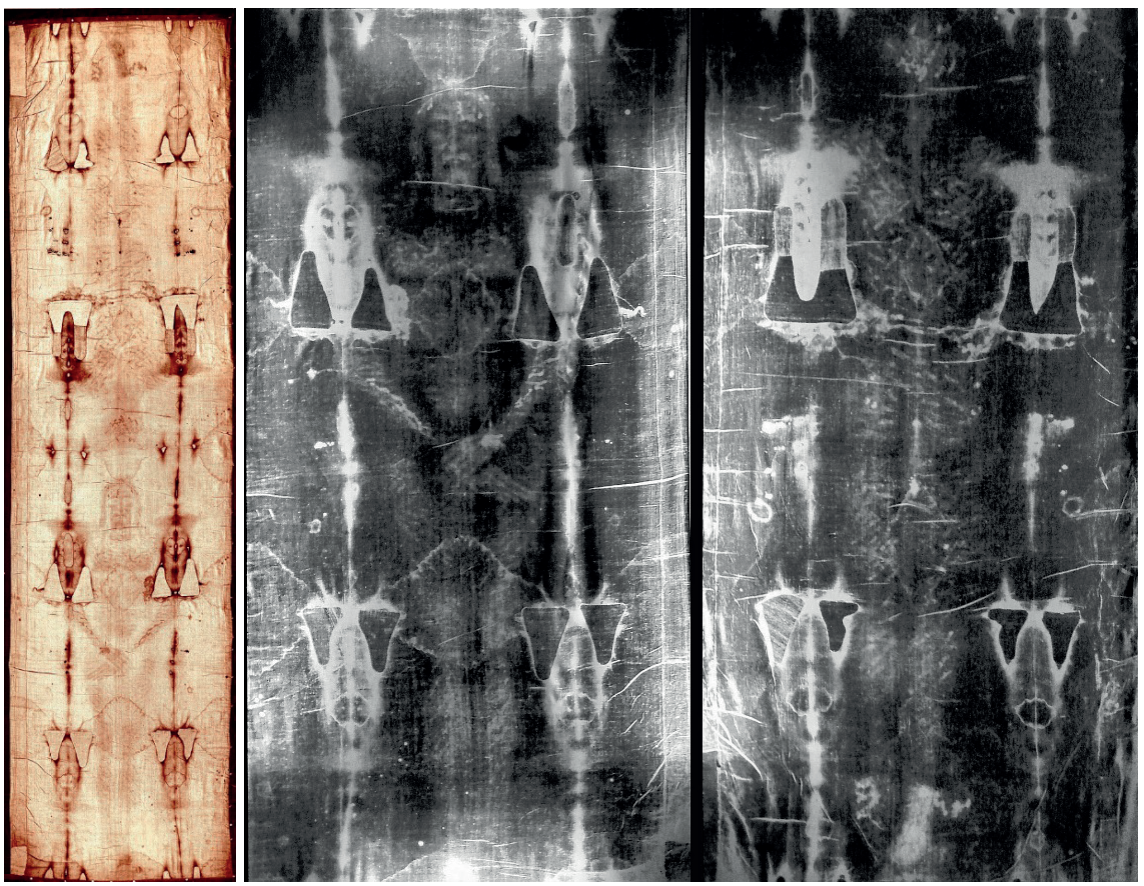

Figura 1. Anverso y reverso del positivo (izquierda) y negativo (derecha) fotográfico de la imagen de la Síndone de Turín. Tomado de Shroud of Turin Education and Research Association, Inc. (STERA, Inc.) 
Además, resultaría difícil a un verdugo tener que clavar los dos pies de un sujeto con un clavo; primero por la defensa que ejercitaría el individuo y segundo porque la postura con los dos pies en paralelo ayudaba al crucificado a elevarse y poder así respirar o hablar y por tanto ayudaba a prolongar más el suplicio. El hecho de que Jesucristo hubiera hablado en siete ocasiones cuando estaba colgado de la cruz, la última con un grito (Marcos 15:37), nos indicaría que esa ayuda en los pies para elevarse y tomar aire podría estar presente. Más aun, en descripciones antiguas se mostraban a los crucificados como montando a caballo sobre la cruz (Flavio Josefo 1755) y, por tanto, con un grado de flexión de las dos piernas en paralelo muy acentuado (Fig. 3). Una postura con los pies cruzados provocaría, además, con el descenso global por el peso del cuerpo, una lateralización de la cadera hacia la izquierda, como así se ve reflejada en algunos cuadros clásicos. Sin embargo, esa lateralización de la cadera no queda tampoco reflejada en la postura de la persona cubierta por la Síndone.
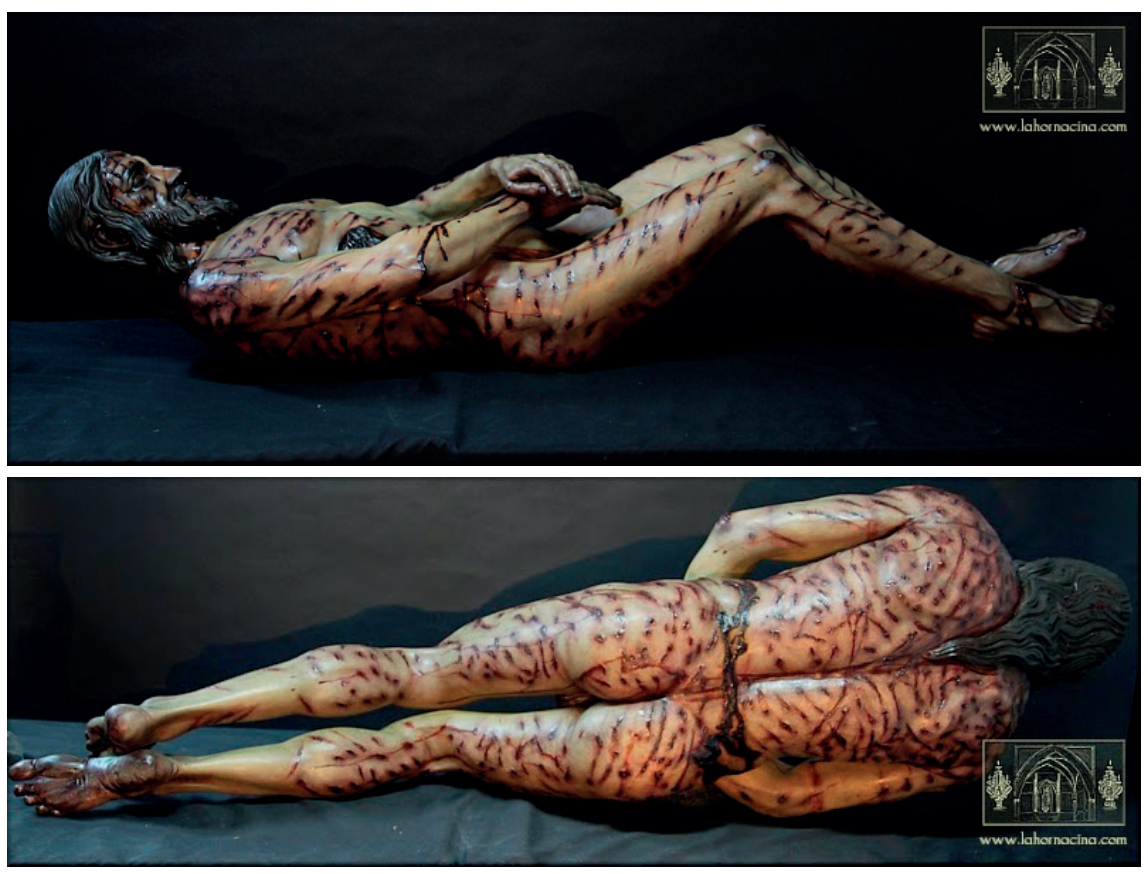

Figura 2. Escultura de José Manuel Miñarro López siguiendo los datos de la imagen de la Síndone de Turín 
Nosotros, teniendo en cuenta estos datos, hemos realizado un dibujo esquemático de cómo sería la figura de Jesucristo al bajar de la cruz en estado de rigidez establecida (Fig. 3). Sin embargo, esta postura de flexión exagerada del cuello a ventral junto con la flexión del tórax y la cabeza descendida no se observa en la Síndone.

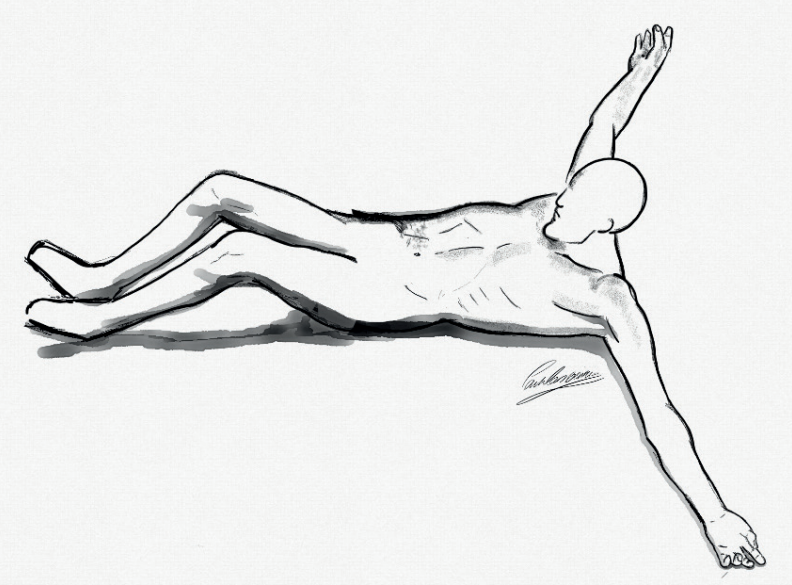

Figura 3. Dibujo esquemático que representa la postura rígida de Jesucristo al ser descendido de la Cruz

Entonces, si la figura que debía haber quedado rígida precozmente en la cruz y descrita por autores antiguos fuera la representada en la figura 3, ¿a qué es debido la presencia de una figura distinta en la sábana? La razón lógica es que los sepultureros, cuando descendieron el cadáver de la cruz, habrían vencido la rigidez de los brazos que se encontraban en abdución (separación) de unos $65^{\circ}$ aproximándolos sobre el cuerpo, en un momento en que la rigidez del cuerpo era poco intensa y todavía vencible. Tenemos que tener en cuenta que, si seguimos ahora el relato evangélico, Jesucristo 
estuvo muerto en la cruz aproximadamente una hora o más. Murió antes que los acompañantes, de hecho, a Él no le fracturaron las piernas, como sí hicieron con los otros dos crucificados porque se hacía tarde y empezaba el sábado. Como Él estaba muerto y los acompañantes vivos vemos que estuvo un lapso de tiempo más o menos prolongado. Al final, porque se acercaba el sábado, aceleraron la muerte de los acompañantes. Después, hubo que pedir el cuerpo a Pilatos por lo que primero hay que ir hasta Pilatos y luego volver hasta el Gólgota. En consecuencia, es razonable pensar que Jesucristo estuvo colgado y muerto entre la hora nona ( $3 \mathrm{pm})$ y antes de empezar la primera vigilia (6 pm) del sábado: entre 1 hora y dos horas ya que había que descolgarlo y sepultarlo antes de que llegara el sábado.

Como ya hemos explicado, al descender a Jesucristo de la cruz éste ya estaría rígido. Sin embargo, lo lógico habría sido que los brazos hubieran sido depositados paralelos al cuerpo y no aducidos (aproximados) a la línea media, tapando los genitales. Se entiende también que los sepultureros en ese mismo momento de depósito del cadáver, y como ya han hecho con los brazos, hubieran vencido fácilmente la hiperflexión de la cabeza hundida en el tórax y la del tronco hasta contactar estos con la superficie de piedra del sepulcro. Si habían podido vencer la separación rígida de los brazos, incluso superándola hacia la línea media, habría sido igual de fácil vencer la flexión de la cabeza y del tronco contra la superficie del suelo. Igualmente, las piernas que deberían estar muy flexionadas y en paralelo por la caída del cuerpo (Fig. 3), habrían sido reducidas a extensión sobre el suelo. Todavía estaban a tiempo de hacerlo ya que la rigidez de ese cadáver era precoz y poco intensa. La posibilidad de que hayan rectificado la rigidez que presentaba el cadáver es altísima teniendo en cuenta que existen restos de mirra y áloe en la sábana (Sccanerini 1997) y por tanto es muy probable que el cuerpo de Cristo pudiera haber sido embadurnado, o masajeado en su superficie. Más aun, el descenso del cuerpo desde la cruz al suelo y a continuación el traslado del cuerpo hasta el sepulcro, muy probablemente no se llevó a cabo en camilla sino que se hizo como se pudo y con prisas, condujo a una manipulación y por tanto rectificación de las articulaciones de miembros superiores, troco y miembros inferiores. En otras 
palabras, no fue depositado el cuerpo sin más una vez bajado de la Cruz con la postura de flexión del tronco, el cuello y las piernas con separación exagerada de los brazos ya que era muy fácil en ese momento reducir esas posturas como ya hemos apuntado. Y, sin embargo, nos encontramos con una imagen que presenta una flexión leve de la cabeza, una semiflexión asimétrica de las rodillas, muslos y tobillos que provoca el apoyo de la planta del pie derecho en la sábana y sólo el talón del pie izquierdo, con una aproximación total de los miembros superiores (los brazos) a la línea media, que ha recibido explicaciones diversas por algunos autores y otros no le dan ninguna explicación, y una ausencia de inclinación de la cadera lateralmente.

Así, no entendemos por qué se afirma que la imagen impresa en la Síndone tiene que haberse producido entre las 4-6 horas después de muerto cuando sabemos que el cadáver ha sido manipulado. No parece tener fundamento realizar esa afirmación teniendo en cuenta que la rigidez es vencible y ha sido manipulado el cadáver durante la sepultura, no solo a nivel de los brazos sino también a nivel de las piernas, el cuello, y probablemente las manos. Además, no coincide la postura con la forma romana de crucificar, revisando otras descripciones de crucificados.

Sin embargo, si tenemos en cuenta el relato evangélico, la forma de crucificar de los romanos y asumiendo que el suppedanium estaba incluido como apoyo, y por tanto cada pie estaba clavado con un clavo, cabe la posibilidad de que esa postura fijada en la Síndone, descrita como de rigidez postmortem, no sea realmente así y se trate de una postura de intento de levantamiento del propio sujeto postmortem. Más aun, las pruebas que hemos realizado a sujetos varones de entre 30 y 40 años con fenotipo atlético de entre 1.70 y $1.80 \mathrm{~m}$ de altura, cuando se les solicita que se levanten partiendo de la posición de decúbito supino y con las manos cruzadas sobre la región suprapúbica, muestran un desplazamiento de estas a los genitales al flexionar el tronco, una elevación y semiflexión de la cabeza y un apoyo de una planta del pie con menos flexión de la pierna contralateral y cierto grado de rotación interna como la observada en la Síndone (Fig. 4). 

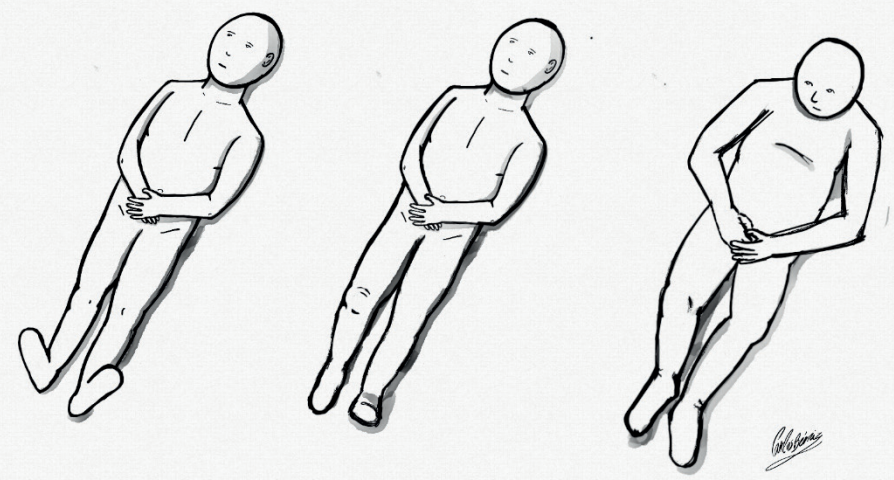

Figura 4. Dibujos esquemáticos de la secuencia de levantamiento de un varón de 36 años y 1.80 m desde la posición de decúbito supino. Nótese la semejanza de la postura con la Síndone de Turín

\section{Aducción (aproximación) de los brazos y antebrazos con cobertura completa de los genitales y aducción (aproximación) de los pulgares}

Observando un poco más profundamente estos signos, se observan en la Síndone unos miembros superiores que no presentan signos de rigidez cadavérica como también lo observan otros autores (Meacham 1983). Este hecho estaría en contraposición con todo lo explicado hasta ahora. Si el momento de máxima rigidez a las 4-6 horas de la muerte observamos la flexión del cuello y miembros inferiores, ¿por qué los miembros superiores no están rígidos si junto con el cuello fueron esos músculos los que más ejercicio soportaron? Una postura rígida de un crucificado implicaría unos antebrazos y unas articulaciones carpianas en semiflexión típica como 
se observa en muchos cadáveres. De ahí la costumbre de atar con vendas brazos y piernas en el pueblo judío como se hizo con Lázaro (Juan 11:44). En los miembros superiores los músculos gravitatorios flexores traccionan más que los antigravitatorios extensores. Sin embargo, la cuasi extensión antigravitatoria de los antebrazos y las manos observada en la Sábana no se le ha dado ninguna explicación (Meacham 1983). Además, las manos con los dedos extendidos parece que están colocados con la intención de no mostrar nada de la genitalidad del sujeto, posición atípica teniendo en cuenta la rigidez propia de un cadáver crucificado. Finalmente, se atribuye a la parálisis del nervio mediano, provocada por los clavos en la muñeca, la ausencia de los pulgares de ambas manos en la imagen de la Síndone (Fig. 1). Es atribuida la postura de aproximación del pulgar hacia la palma de la mano cuando existe una parálisis del nervio mediano, predominando la actividad del nervio cubital sobre el aductor del pulgar, y por tanto acercando el mismo hacia la palma de la mano. Sin embargo, independientemente de que se haya producido dicha lesión nerviosa, no se produce una aposición del pulgar sobre la palma de la mano. En una lesión distal del nervio mediano el pulgar se pone en el mismo plano que los otros cuatro dedos y pegado al índice, lo que se denomina mano en simio. Por tanto, los pulgares deberían verse en la Síndone al tener una parálisis del nervio mediano distal. Así, esta ausencia de los pulgares en la Síndone también es explicable cuando el pulgar de la mano izquierda, que está por encima de la derecha, está abrazando ventralmente la muñeca derecha en vez de estar, como se ha atribuido por la parálisis, en aproximación o aducción hacia la palma de la mano. Igualmente, el pulgar de la mano derecha sencillamente queda oculto por la mano izquierda. Por tanto, es razonable pensar que también la ausencia de los pulgares en la Síndone puede atribuirse bien a signos de vida o a una modificación de la postura de las manos por parte de los enterradores en vez de sólo a la parálisis de un cadáver rígido. Además, y abundando más en esta idea, , las falanges distales de los dedos índice, medio y anular de la mano derecha están en semiflexión comparado con la mano izquierda que están en extensión, postura difícilmente preparada por un sepulturero. 


\section{Presencia de surcos nasogenianos y nasolabiales en la cara}

Quizá este sea un signo todavía más sorprendente, si cabe, por varios motivos. Los surcos nasogeniano y nasolabial son unos surcos que aparecen de forma bilateral por la tracción de determinados músculos faciales (Barton and Gyimesi 1997). Este surco se forma cuando la musculatura que tracciona en dirección ascendente y oblicua al labio superior impide que la piel de la mejilla y su compartimento graso, con contenido más elástico, se descuelgue sobre la piel del labio superior a medida que la edad aumenta (Fig. 5 izquierda). Estos surcos, dependiendo del fenotipo de la persona, suelen aparecer a partir de los 25 años. Cuanto más edad y delgadez tiene la persona más marcados serán los surcos. El surco desaparece cuando hay una parálisis facial del lado afecto (Fig. 5 derecha). Cuando hay una parálisis facial bilateral, los dos surcos desaparecen. Una situación de parálisis facial bilateral aparece en la muerte al relajarse la musculatura tractora.
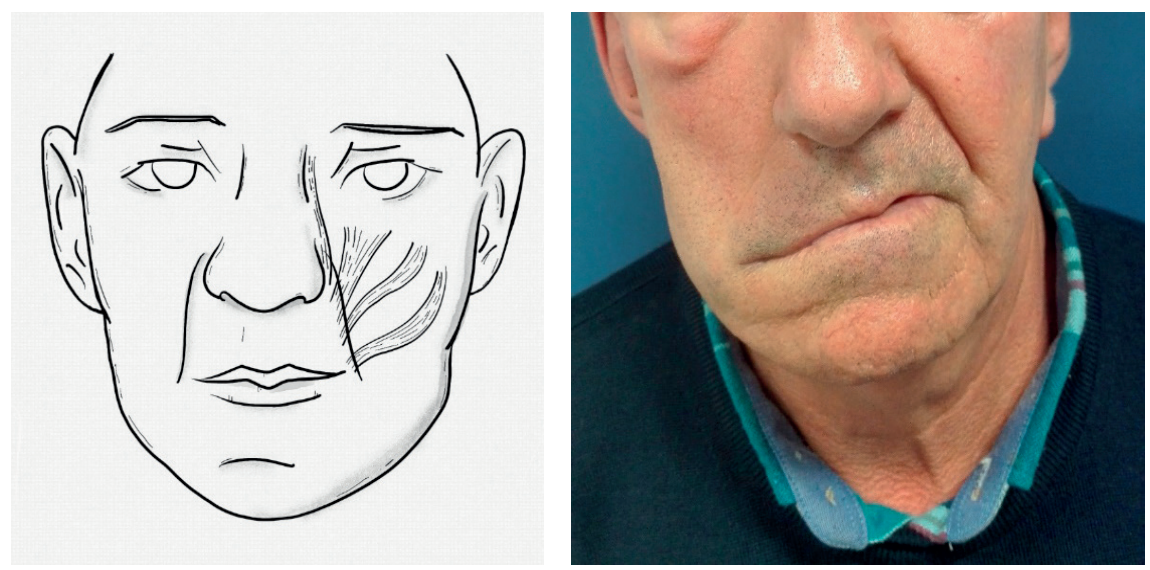

Figura 5. (Izquierda) Dibujo esquemático mostrando la formación de los surcos nasogeniano y nasolabial por la actividad de la musculatura cigomática mayor y menor y elevador del labio superior y ángulo de la boca. (Derecha) Paciente con parálisis facial. Nótese el borramiento del surco en el lado derecho de la parálisis 
En un cadáver reciente la musculatura facial se relaja (Wilkinson y Rynn 2011) y desaparecen los surcos (se aplanan enormemente en personas con una profundidad de surco muy marcada), el labio inferior desciende (el descenso sería más acusado en una muerte en una posición vertical) y se abre la boca. Este es el momento inicial de flacidez postmortem. Es una práctica habitual hoy en día que, durante la preparación de los cadáveres, se coloque una almohada en la nuca para provocar la flexión de la misma y así mantener la mandíbula contra el tórax y por tanto la boca cerrada. La presencia de estos surcos en la cara impresa en la Síndone (Fig. 6) nos lleva en un primer momento a pensar que la persona de la sábana o está viva o podría justificarse por un fenómeno de rigidez postmortem. Vamos a analizar esta segunda opción como la más creíble de inicio. En primer lugar, no existen cadáveres que durante el período de rigidez postmortem marquen más acentuadamente los surcos nasogenianos. La única posibilidad de que así fuera podría tener como explicación que hubiera muerto con una expresión de agonía frente al dolor tan grande sufrido, que incluso debería exponer toda la arcada dental superior e inferior. Este espasmo cadavérico sería similar al que aparece en la mano del suicida que agarra el arma. La tensión emocional hace que el sujeto empuñe el arma de forma excesiva y quede la postura fijada en el cadáver reciente. Ese empuñamiento lo diferenciaría del que ha sido asesinado y se le ha colocado el arma en la mano a posteriori. En este último caso, la mano no agarra el arma lo que lo distinguiría del suicidio. Aun así, no se conocen casos de individuos que, teniendo un sufrimiento atroz con expresión de horror en la cara, al morir, hayan fijado esa expresión en forma de espasmo cadavérico. En el caso que nos ocupa, la expresión facial que presenta se asemeja más a una persona dormida que muerta ya que durante el sueño se mantiene el tono muscular involuntario y por tanto la presencia moderada, no exagerada, de los surcos excluiría el espasmo facial por sufrimiento del que venimos hablando.

Disecando un poco más en profundidad la imagen de la mejilla derecha vemos cómo en el tercio superior de la región malar existe un abultamiento compatible con un traumatismo que se delimita más caudalmente con 
otro surco en paralelo (Fig. 6, surco superior) al surco nasogeniano y que es típico de las personas vivas que tienen activada la tracción de ese surco por la musculatura subyacente que contribuye a formar ese doble pliegue. Si la persona estuviera muerta la relajación del surco nasogeniano y nasolabial no impediría el descenso del surco inflamatorio (línea superior) observándose una inflamación generalizada de toda la mejilla derecha, respecto de la izquierda, pero sin la formación de surcos. Más aún, el labio inferior se encuentra pegado al labio superior, lo que indicaría tono de la musculatura facial.

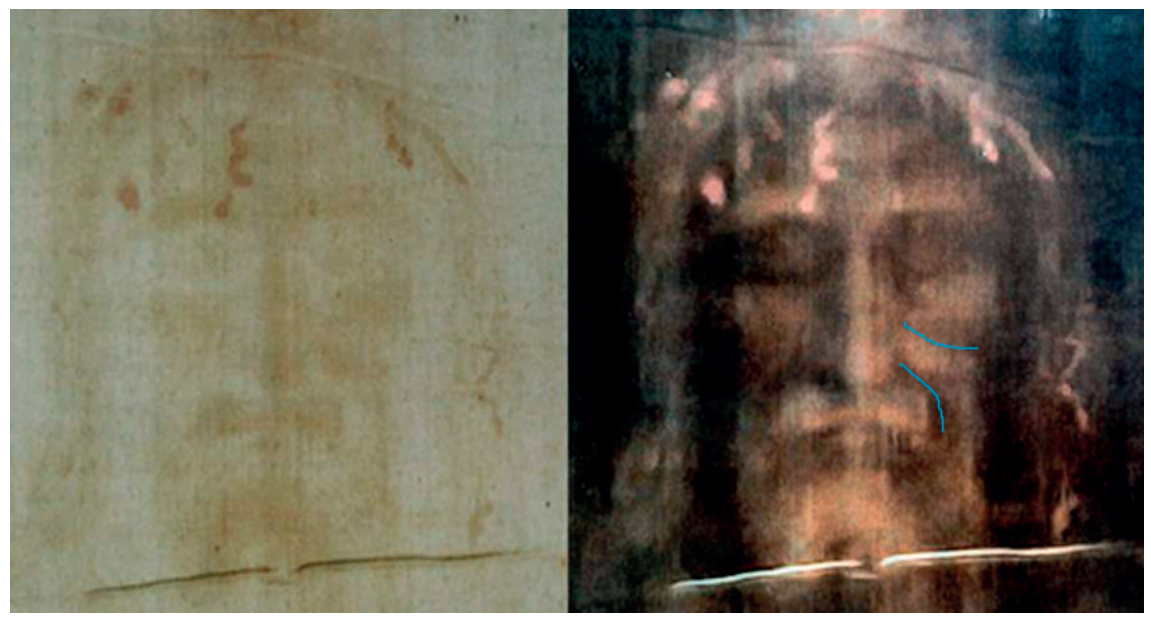

Figura 6. Imagen de la cara de la Síndone de Turín a la izquierda y la foto del negativo a la derecha. En el lado derecho de la cara (imagen invertida) se muestra el surco nasogeniano y nasolabial y cranealmente el surco inflamatorio. La flecha roja apunta al surco inflamatorio. El surco superior es el surco nasonasogeniano y nasolabial. El surco inferior es el surco nasonasogeniano y nasolabial. Fotografía tomada de Shroud of Turin Education and Research Association, Inc. (STERA, Inc.)

Por tanto, cabe dar una explicación distinta al origen de la posición de la imagen de la Síndone que difiere de la atribuida a la rigidez postmortem. Así, teniendo en cuenta que los períodos de rigidez ya expuestos no explicarían la posición del cadáver, teniendo en cuenta que el cadáver ha sido 
manipulado en un estado de rigidez poco intensa y vencible y teniendo en cuenta la forma de crucificar romana con cuatro clavos, cabría pensar la posibilidad de que la imagen se formó en un período en el que el sujeto no estaba sometido a ningún efecto de la rigidez postmortem. Así, la postura de semiflexión asimétrica que se observa en las piernas, la semiflexión de la cabeza, y sobre todo la presencia de los surcos nasogenianos marcados a nivel facial y la colocación de las manos sobre los genitales, podría indicar que estamos delante de una persona que está iniciando un movimiento de levantamiento y por tanto de acortamiento muscular voluntario. Esta imagen dinámica, si no tenemos en cuenta los textos históricos descritos en los evangelios, pudo haberse producido en cualquier momento entre el cerramiento de la tumba y las 30 horas siguientes a la muerte, pero estando vivo.

Podría objetarse que la postura que presenta la imagen de la Síndone pueda ser debida a que, una vez vencida la rigidez del cadáver por los sepultureros como ya hemos indicado, esta se haya podido recuperar en cierta medida, y en menor grado, a lo largo de las horas. Podríamos decir que es como si el cadáver tuviera una cierta memoria a recuperar en menor intensidad la posición exagerada que tuvo al morir. Dudamos de que esto haya podido ocurrir así porque la rectificación de la postura del cadáver hace que el cuerpo se quede fijo en esa nueva postura. Además, la rigidez era poco intensa y no explicaría qué sólo haya ocurrido con la cabeza y con las piernas, pero no haya ocurrido con los brazos que permanecen en aproximación forzada hacia la línea media en vez de separados del tronco intentando recuperar la postura como cuando estaba crucificado.

Si tenemos en cuenta el relato evangélico, hay un hecho que pudo ocurrir, aunque es una hipótesis, y es que la imagen no pudo formarse antes de las 8-10 am del sábado (18 horas postmortem) ya que, según está escrito en Los Evangelios, los judíos al conocer que un miembro del Sanedrín (José de Arimatea) ha sepultado el cadáver en un sepulcro suyo, estos temen que vaya a ser robado. Esa conversación con Pilato no se produce el mismo viernes, ya que se fueron golpeándose el pecho el mismo viernes al atardecer y había que respetar el sábado que comenzaba después de la hora décima (las 18-19 pm). 
La conversación tuvo lugar el sábado por la mañana en la que, después de reunirse ellos, solicitan una guardia a Pilatos para ir a vigilar la tumba durante al menos tres días (Mateo 27:62), que era lo que Jesús había anunciado. Por tanto, por la mañana del mismo sábado, sin respetar el descanso del día tan señalado, acudirían a comprobar primero que durante la noche anterior no se habría producido el robo. Abrirían la tumba, levantarían la sábana que cubría el cuerpo, comprobarían que era Él y no otro y que seguía muerto para después cerrar la tumba poniendo el sello de Sanedrín (Mateo $27: 67)$. No tiene sentido hacer guardia delante de una tumba si la cadena de custodia se ha interrumpido en algún momento como así fue, y si se ha interrumpido se comprueba que efectivamente está el sujeto en la tumba y muerto. En consecuencia, hasta después de las 8-10 am del sábado (18-20 horas postmortem) y antes de las $12 \mathrm{pm}-2$ am (unas 30 horas postmortem) del sábado no se produciría la imagen en la sábana. Más allá de las 30 horas postmortem, el cadáver de un crucificado sin reservas de glucógeno, desangrado y deshidratado y con una temperatura moderadamente cálida en el exterior, se hubiera empezado a descomponer y se hubieran encontrado signos de putrefacción en la Síndone, como no ha sido así. Hay que tener en cuenta que con la temperatura externa de unos 20 grados en Jerusalén en el mes de abril más de tres días, Jesucristo, en sus condiciones traumáticas, se hubiera empezado a descomponer en la madrugada del domingo, como muy tarde. Lázaro al cuarto día ya olía (Juan 2, 39).

Continuando con el relato evangélico, si el anuncio de su resurrección era al tercer día, este comienza a partir de la primera vigilia (nuestras 19-20 pm del sábado o cuando aparece la primera estrella en el firmamento). Por tanto, la imagen que queda impresa en la Sábana podría producirse cuando Jesucristo inicia un movimiento de levantamiento entre la primera vigilia del domingo (19-21 horas del sábado) y segunda vigilia (21-24 horas) o, como mucho, el inicio de la tercera vigilia del domingo ( 24 horas $-3 \mathrm{am}$ ) del tercer día después de su muerte. Ese primer e incipiente signo de levantamiento pudo ocurrir en décimas o segundos para después desvanecerse el cuerpo y atravesar el lienzo. No encontramos explicación a las milésimas o décimas de segundo posteriores a la impresión de la imagen. 
Llegados a este punto, pensamos que la imagen impresa en la Síndone es la de una persona que está viva. Así, tenemos sólo dos opciones para explicarla. La primera es, si obviamos por completo el relato histórico de los Evangelios, que se envolvió a esa persona viva presentando los signos de maltrato presentes en la Síndone (latigazos, corona de espinas, clavos en los miembros). Envolver a alguien vivo nos devolvería a pensar que la sábana es un fraude y nos obligaría a cargar la veracidad de la prueba en la propia antigüedad de la Sábana y el enigma continuaría en saber cómo se llevó a cabo el procesamiento de esa imagen. Sin embargo, existen evidencias que sugieren que algunos de los depósitos de sangre en la imagen anteceden al desarrollo de la propia imagen (Bucklin 1982) lo que indicaría que, tanto la sangre premortem y postmortem que impregnan la Sábana, muestran que el sujeto estaba vivo y después murió y tras morir apareció la imagen. En consecuencia, no es posible que la imagen impresa en la Síndone, de naturaleza distinta, complementaria y no superpuesta a la de las manchas de los coágulos de sangre, pueda proceder de un sujeto muerto. En realidad, es muy difícil de explicar cómo en el siglo XIV, y en realidad en cualquier otro siglo, alguien pudo diseñar material y formalmente la imagen de un sujeto muerto y a la vez vivo. Podríamos calificar el fraude como de una verdadera obra de arte realizada por alguien con conocimientos médicos, conocimientos forenses del proceso cronotanatobiológico postmortem y de procesamiento de imágenes en tejidos antiguos, entre otros conocimientos. Casi diríamos que la producción de esa imagen en ese objeto es absolutamente admirable, por no decir milagroso, que se sale fuera de toda lógica humana sobre todo si es llevada a cabo por una o varias personas previas al siglo XIV y casi diría de cualquier siglo.

Una segunda opción es, si tenemos en cuenta el relato evangélico, que se trata de un lienzo que perteneció a un rabino judío (la coleta presente en la cara posterior de la imagen lo identifica como rabino) que fue enterrado según la tradición judía después de haber sido crucificado y flagelado según la costumbre romana y de forma coherente a como se describe en los evangelios, tal y como apuntaba Schwortz. Y nosotros podemos añadir, a diferencia de Schwortz y otros autores, que la imagen se produjo cuando estaba vivo y no 
cuando era cadáver ya que contiene los signos estáticos propios de una persona muerta (flagelación, sangrados premortem y postmortem) y que a la vez presenta signos dinámicos de vida (surcos nasogenianos marcados, la posición de las manos sobre los genitales, están intencionadamente cubiertos, y los signos de levantamiento) en contradicción con la secuencia natural de la aparición de los signos de rigidez cadavérica. Además, todo ello coincidiendo en fecha con la tarde noche del sábado que, como bien se sabe, coincidiría con el inicio del tercer día, como viene descrito en los evangelios. Si la Síndone cubrió el cuerpo de Jesús es razonable pensar que a Él le interesaría no sólo mostrarnos los signos de muerte sino también de resurrección en el mismo objeto. Así, analizando los tiempos transcurridos desde la muerte a la resurrección, y siguiendo el relato evangélico, parece que Jesucristo quiso morir a esa hora, coincidiendo con el sacrificio de los corderos en el pueblo judío, calculando el tiempo suficiente del tercer día sin que su cadáver soportara la corrupción. Insistimos en el verbo "quiso" ya que hasta el propio Pilatos se sorprendió de que hubiera muerto tan pronto (Marcos 15:44).

En opinión del autor, si una imagen similar perteneciera a un lienzo que cubriera el cuerpo de Tutankamon o de Julio César siguiendo las descripciones históricas sobre su muerte, no existiría ninguna duda sobre su veracidad. La simetría y coherencia entre los datos que nos aporta la Sábana y el relato evangélico, tanto en la descripción de la muerte como en la resurrección, es tan perfecta que resulta más complicado demostrar que la Síndone, siendo una verdadera obra de arte, es en realidad un fraude antes que asumir la simpleza de la realidad de su propia veracidad histórica en relación con los hechos descritos en los Evangelios.

\section{Conclusión}

El presente estudio nos permite concluir que la imagen presente en la Síndone de Turín pertenece a una persona viva y no cadáver como se ha venido describiendo. Si no tenemos en cuenta el relato evangélico no tiene explicación, por el momento, el origen de la imagen tanto desde el punto de vista material como formal y debería ser considerada una obra de arte 
realizada por un genio excepcional. Por el contrario, analizando la secuencia histórica narrada en los evangelios existe una simetría absoluta entre los datos que se muestran en la imagen y lo narrado en los mismos, tanto de la muerte como de la resurrección de Jesús.

\section{Agradecimientos}

Quiero agradecer al profesor José Manuel Giménez Amaya los comentarios realizados para llevar a cabo este artículo. Igualmente, a Carlos Bérniz por la elaboración de los dibujos y a Andrés Ros por la ayuda en la búsqueda bibliográfica.

\section{Referencias}

Arnaud. 1880. De l'attitude des morts sur les champs de bataille. Recuil des memoires de medicine militaire. Cit. Royo-Villanova.

Barbet, Pierre. 1953. A Doctor at Calvary: The Passion of Our Lord Jesus Christ As Described by a Surgeon. New York: P.J. Kenedy.

Barton, Fritz E., and Gyimesi Ildiko M. 1997. "Anatomy of the nasolabial fold". Plast Reconstr. Surg. 10: 1276-1280.

Borrini, Mateo, and Luigi Garlaschelli. 2019. "A BPA Approach to the Shroud of Turin”. J Forensic Sci. 64:137-143. DOI: 10.1111/1556-4029.13867.

Bucklin, Robert. 1982. "The Shroud of Turin: viewpoint of a forensic pathologist". Shroud Spectrum International 5: 3-10.

Burkhard, Madea. 2006. The estimation of the time since death. The Student's HandBook of Forensic Medicine and Medical Police. Tylor and Francis group. Florida.

De Cartago, San Cipriano. 2016. “Sermón sobre la pasión”. In Obras completas de San Cipriano de Cartago. Translated and edited by Juan Antonio Gil-Tamayo. Madrid: Biblioteca de Autores Cristianos.

Fanti, Gulio. 2010. "Can a Corona Discharge Explain the Body Image of the Turin Shroud?”. Journal of Imaging Science and Technology, 54: 20508-1-20508-11. DOI: https://doi.org/10.2352/J.ImagingSci.Technol.2010.54.2.020508.

Fernández-Capo, José. 2015. "Faith and science dialogue in the Shroud of Turin". Scientia et Fides. 3: 37-59. DOI: http://dx.doi.org/10.12775/SetF.2015.001.

Fernández-Carvajal, Francisco. 1997. La Vida de Jesús. Madrid: Ediciones Palabra S.A. Fisher, Barry A., and David R. Fisher. 2012. Techniques of crime scene investigation. Ed. Taylor and Francis group. $8^{\text {th }}$ edition. Boca Ratón. Florida. 
Flavio Josefo. 1755. De bello iudaico. Cambridge: Typis Academicis.

https://es.weatherspark.com > Israel > Jerusalem.

https://www.shroud.com/

Humphreys, Colin J. y William D. Waddington. 1983. “Dating the crucifixion”. Nature 306; 743-746. DOI: 10.1038/306743a0.

Kori, Shivpoojan. 2018. "Time since death from rigor mortis: Forensic prospective”.

J Forensic Sci \& Criminal Inves. 9: 1-10. DOI: 10.19080/JFSCI.2018.09.5557710010.

Löring, Jorge. 2006. La Sábana Santa dos mil años después. Barcelona: Planeta DeAgostini.

Martins, Pedro A., Francisca Ferreira, Renato Natal Jorge, Marco Parente, and Agostinho Santos Agostinho. 2015. "Necromechanics: Death-induced changes in the mechanical properties of human tissues”. Proc Inst Mech Eng H. 229:343-9. DOI: $10.1177 / 0954411915581409$.

Meacham, William. 1983. "The authentication of the Turin Shroud: An issue in archaeological epistemology”. Current anthropology 24(3): 283-311.

Sccanerini, Silvano. 1997. Mirra, áloe pollini e altre trace. Ricerca botánica sulla Sindone. Torino: Elle Di Ci.

Schneible, Ann. ¿Cómo un científico escéptico llegó a creer en la Sábana Santa? ACI Prensa/EWTN Noticias. 10 de agosto de 2015. https:/www.aciprensa.com/ noticias/el-claro-testimonio-del-cientifico-judio-que-cree-y-defiende-la-sabana-santa-de-turin-91516.

Tertuliano. De anima 56, 8-57, 3; CC 11, 864 s.

Villalaín, José D. 2010. “Estudio de la rigidez cadavérica que presenta la Síndone de Turín”. Cuad. Med. Forense. 16: 109-123.

Wilkinson, Caroline, and Christopher Rynn. 2012. "Post-mortem prediction of facial appearance”. In Craniofacial Identification. 166-183. New York: Cambridge University Press.

Zias, Josue. 1985. "Leprosy and tuberculosis in the Byzantine monasteries of the Judean Desert”. Korot, 9: 242-248. 